\title{
Balloon-borne observations of midlatitude fluorine abundance
}

\author{
B. Sen, G.C. Toon, and J.-F. Blavier \\ Jet Propulsion Laboratory, California Institute of Technology, Pasadena \\ E.L. Fleming \\ Applied Research Corporation, Landover, Maryland \\ C.H. Jackman \\ Laboratory for Atmospheres, NASA Goddard Space Flight Center, Greenbelt, Maryland
}

\begin{abstract}
Volume mixing ratio profiles of fluorine source gases $\left(\mathrm{CF}_{2} \mathrm{Cl}_{2}, \mathrm{CFCl}_{3}, \mathrm{CF}_{2} \mathrm{ClCFCl}_{2}\right.$, $\mathrm{CHF}_{2} \mathrm{Cl}, \mathrm{CF}_{4}$, and $\left.\mathrm{SF}_{6}\right)$ and reservoir gases $\left(\mathrm{COF}_{2}\right.$ and $\left.\mathrm{HF}\right)$ have been derived from a series of high-resolution infrared solar spectra recorded by the Jet Propulsion Laboratory MkIV interferometer during a September 1993 balloon flight from Fort Sumner, New Mexico $\left(34^{\circ} \mathrm{N}\right.$, $104^{\circ} \mathrm{W}$ ). The total fluorine budget over the 5- to $38-\mathrm{km}$ altitude range has been evaluated by adding these individual measured profiles to modeled predictions for the unmeasured gas $\mathrm{COFCl}$ (considered to be at most $6 \%$ of the total fluorine budget). The results indicate a steady decrease of total fluorine, with increasing altitude, from a tropospheric value of about 1.82 parts per billion by volume (ppbv) to $1.48 \mathrm{ppbv}$ at $38 \mathrm{~km}$. The latter value, made up entirely of the reservoir species, is commensurate with tropospheric concentrations of fluorine reported in the late $1980 \mathrm{~s}$ and with time-dependent two-dimensional model predictions (1.45 ppbv). Therefore the "age" of the stratospheric air mass estimated from the MkIV fluorine budget is 4-5 years, in agreement with model simulations ( $\approx 6$ years) and recent ATMOS measurements.
\end{abstract}

\section{Introduction}

The tropospheric lifetimes of most chlorofluorocarbons (CFCs) and hydrofluorochlorocarbons (HCFCs) are sufficiently long to allow them to be transported to the stratosphere, where their chlorine atoms are removed, and then participate in the catalytic destruction of ozone. Removal of fluorine atoms from CFCs and HCFCs is more difficult; and generally occurs in the later stages of the breakdown and at slightly higher altitudes. Unlike atomic chlorine and bromine the reactions of atomic fluorine with $\mathrm{CH}_{4}$ and $\mathrm{H}_{2} \mathrm{O}$ are very fast, and fluorine is thus efficiently removed to form hydrogen fluoride (HF). HF is not recycled back into active forms of fluorine and is therefore believed not to participate in any catalytic cycle that significantly depletes ozone [Stolarski and Rundel, 1975].

The CFCs and HCFCs are strong mid-infrared absorbers and can cause significant radiative forcing of the surface-troposphere system. Coupled with other long-lived and "well-mixed" greenhouse gases (such as $\mathrm{CO}_{2}, \mathrm{CH}_{4}$, and $\mathrm{N}_{2} \mathrm{O}$ ) the change in net irradiance at the tropopause between the years 1980 and 1990 was about $0.45 \mathrm{~W} \mathrm{~m}^{-2}$, almost 4 times bigger than the cooling caused by stratospheric ozone depletion during the same period [World Meteorological Organization (hereafter WMO), 1994]. The future radiative forcing and hence climate changes will thus depend upon the time-dependent mix of anthropogenic source gases in the stratosphere. Measurements of F-containing species in the atmosphere uniquely reflect the amounts of anthropogenic gases transported into the middle atmosphere and available for

Copyright 1996 by the American Geophysical Union.

Paper number 96JD00227.

0148-0227/96/96JD-00227\$05.00 participation in (1) the catalytic destruction of ozone, (2) the indirect cooling of the lower stratosphere due to ozone loss, and (3) the direct heating of the troposphere.

The purpose of this paper is to describe in detail the MkIV measurements of fluorine species in the troposphere and stratosphere. We define fluorine sources as gases whose volume mixing ratio (vmr) profile exhibits a maximum in the troposphere, and fluorine reservoirs as gases whose vmr peaks above the tropopause. We first review our understanding of the chemical degradation of CFCs and HCFCs in the atmosphere and describe the mechanism by which fluorine source gases are broken down to reservoir species. We then describe the balloon flight on which the solar observations were performed and summarize the data reduction techniques and the retrieval of vmr profiles. Results for the individual fluorine-bearing gases are compared with previous measurements and collated in terms of their contribution to the fluorine budget in the atmosphere. Finally, the MkIV measurements of total fluorine abundance in the atmosphere are compared with two-dimensional (2-D) model simulations and ATMOS measurements.

\section{Chemistry of Stratospheric Fluorine}

The release of fluorine from the $\mathrm{CFCs}$ is believed to be analogous to the better-known $\mathrm{CH}_{4}$ oxidation scheme. $\mathrm{CFC}$ oxidation in the stratosphere occurs with the break of a $\mathrm{C}-\mathrm{Cl}$ bond and continues with the breaking of the remaining $\mathrm{C}-\mathrm{Cl}$ bonds before any of the C-Fs [Kaye et al., 1991]. In the case of HCFCs, the $\mathrm{C}-\mathrm{H}$ bonds break first.

CFCs (and HCFCs) containing two fluorine atoms are first broken down to $\mathrm{CF}_{2} \mathrm{Cl}$ (e.g., $\mathrm{CHF}_{2} \mathrm{Cl}+\mathrm{OH} \rightarrow \mathrm{CF}_{2} \mathrm{Cl}+\mathrm{H}_{2} \mathrm{O}$, $\mathrm{CF}_{2} \mathrm{Cl}_{2}+\mathrm{hv} \rightarrow \mathrm{CF}_{2} \mathrm{Cl}+\mathrm{Cl}$ ), which then undergoes the following chain of reactions: 


$$
\begin{gathered}
\mathrm{CF}_{2} \mathrm{Cl}+\mathrm{O}_{2}+\mathrm{M} \rightarrow \mathrm{CF}_{2} \mathrm{ClO}_{2}+\mathrm{M} \\
\mathrm{CF}_{2} \mathrm{ClO}_{2}+\mathrm{NO} \rightarrow \mathrm{CF}_{2} \mathrm{ClO}+\mathrm{NO}_{2} \\
\mathrm{CF}_{2} \mathrm{ClO}+\mathrm{O}_{2} \rightarrow \mathrm{CF}_{2} \mathrm{O}+\mathrm{ClO}_{2} \\
\mathrm{CF}_{2} \mathrm{O}+\mathrm{hv} \rightarrow \mathrm{FCO}+\mathrm{F}
\end{gathered}
$$

The temporary reservoir $\mathrm{COF}_{2}$ is quite stable and is only slowly photolyzed.

CFCs with a single fluorine atom are initially broken down to $\mathrm{CFCl}_{2}$ (e.g., $\mathrm{CFCl}_{3}+\mathrm{hv} \rightarrow \mathrm{CFCl}_{2}+\mathrm{Cl}$ ), which then undergoes a similar chain of reactions:

$$
\begin{gathered}
\mathrm{CFCl}_{2}+\mathrm{O}_{2}+\mathrm{M} \rightarrow \mathrm{CFCl}_{2} \mathrm{O}_{2}+\mathrm{M} \\
\mathrm{CFCl}_{2} \mathrm{O}_{2}+\mathrm{NO} \rightarrow \mathrm{CFCl}_{2} \mathrm{O}+\mathrm{NO}_{2} \\
\mathrm{CFCl}_{2} \mathrm{O}+\mathrm{O}_{2} \rightarrow \mathrm{CFClO}+\mathrm{ClO}_{2} \\
\mathrm{CFClO}+\mathrm{hv} \rightarrow \mathrm{FCO}+\mathrm{Cl}
\end{gathered}
$$

The CFO produced from this and the previous reaction chain reacts with $\mathrm{O}_{2}$ :

$$
\mathrm{FCO}+\mathrm{O}_{2} \rightarrow \mathrm{FC}(\mathrm{O}) \mathrm{O}_{2} \rightarrow \mathrm{FO}+\mathrm{CO}_{2}
$$

to form FO. The fluorine is removed from FO by its reaction with $O\left({ }^{\prime} D\right)$ :

$$
\mathrm{FO}+\mathrm{O}\left({ }^{1} D\right) \rightarrow \mathrm{F}+\mathrm{O}_{2}
$$

The $\mathrm{F}$ atoms produces by this reaction and the earlier reactions quickly combine with $\mathrm{H}_{2} \mathrm{O}$ and $\mathrm{CH}_{4}$ to produce $\mathrm{HF}$, which undergoes almost no further chemical changes and is lost from the stratosphere through a slow diffusion into the troposphere and eventual rainout.

The remaining fluorine-containing source gas of importance, from the emission scenarios, $\mathrm{CF}_{2} \mathrm{ClCFCl}_{2}$ (CFC-113), is lost via photolysis and reactions with $O\left({ }^{1} D\right)$.

\section{Instrument and Balloon Measurements}

The latest in a series of solar absorption Fourier Transform infrared (FTIR) spectrometers designed at Jet Propulsion Laboratory (JPL), the MkIV interferometer [Toon, 1991] uses the occultation technique to remotely measure the atmospheric composition. The high spectral resolution $\left(0.01 \mathrm{~cm}^{-1}\right)$ and broad spectral coverage $\left(650-5650 \mathrm{~cm}^{-1}\right)$ of the MkIV instrument allow it to measure a large number of different gases simultaneously in the same air mass. MkIV uses two cryogenically cooled detectors: a $\mathrm{HgCdTe}$ photoconductor for frequencies below $1850 \mathrm{~cm}^{-1}$ and an InSb photovoltaic for frequencies above $1850 \mathrm{~cm}^{-1}$. This arrangement prevents photons from the high frequencies where the Sun is bright from degrading the weaker signal at lower frequencies and yields a spectrum with signal-to-noise ratio exceeding 400:1 over the entire spectral range. More important, these spectra have excellent zero offsets, since the nonlinearity of the $\mathrm{HgCdTe}$ photoconductor can be corrected over its limited interval and the InSb photodiode is intrinsically highly linear.

The sunset occultation spectra analyzed in this work were acquired from $38 \mathrm{~km}$ altitude during a balloon flight launched from Fort Sumner, New Mexico $\left(34.48^{\circ} \mathrm{N}, 104.22^{\circ} \mathrm{W}\right)$ on September 25,1993 . The flight was exceptional in that a very clear troposphere allowed us to track the Sun down to the surface ( $3 \mathrm{~km}$ altitude). However, the last interferogram was incomplete and therefore not used in the present analysis. An unapodized spectral resolution of $0.0075 \mathrm{~cm}^{-1}(66 \mathrm{~cm}$ maximum path difference) was employed at solar zenith angles up to $93^{\circ}(\approx 28$ $\mathrm{km}$ altitude), at which point we switched to $0.015 \mathrm{~cm}^{-1}$ resolution to allow more rapid sampling, and thereby keep the tangent point separation of successive pairs of spectra in the 2- to 3-km range. Each analyzed spectral pair (forward \& reverse) therefore represents 100 or 200 seconds of observations. Fifteen spectral pairs were acquired during the $38 \mathrm{~min}$ of sunset observations.

\section{Data Analysis}

Before analyzing any limb spectra a "high-Sun" spectrum was computed by averaging the lowest air mass spectra, acquired during early afternoon from a height of $38 \mathrm{~km}$. Each sunset spectrum was then divided by this "high-Sun" spectrum to eliminate solar and instrumental absorption features which could otherwise lead to systematic errors in the retrieved vmr profiles.

Data analysis proceeded by a two-step approach. First, a nonlinear least squares (NLLS) fitting algorithm was used to determine the slant column abundances for each target gas in each spectrum. Then a linear equation solver was used to retrieve vmr profiles. This entire spectral fitting and retrieval process was then repeated, using the new retrieved vmr profile as the initial guess.

\section{Spectral Fitting}

The NLLS algorithm performed simultaneous adjustments to the gas abundances, the continuum level, its tilt, and the frequency shift to minimize the residual between the computed and measured spectrum. The slant column was then computed by numerical integration of the final vmr profiles. The error in the slant column was computed from the spectral residuals and includes contributions from the covariances of the other fitted parameters, as well as uncertainty in the spectrum zero level. For gases involving more than one spectral interval a weighted average slant column was calculated.

\section{Profile Retrieval}

The slant columns, together with the matrix of computed geometrical slant path distances, were next inverted, by using a linear equation solver, subject to a derivative constraint. This yielded vmr profiles from $5 \mathrm{~km}$ up to $38 \mathrm{~km}$, the balloon altitude. The vertical separation of the retrieved $\mathrm{vmr}$ profiles was chosen to be $1 \mathrm{~km}$, despite the tangent point spacing being $2-3 \mathrm{~km}$. There are two reasons for this choice: (1) to be compatible with the forward model inputs and (2) not to degrade the high vertical resolution immediately below the balloon where the tangent point separation is small. The reported error in the retrieval of vmr represents the relative precision of the retrieval at the various levels. These are the changes to the vmr that would change the slant columns by their one sigma uncertainties. Retrieved vmr values were allowed to go negative so as not to positively bias the profiles and hence the total fluorine. The few negative retrieved vmrs are nearly all smaller than their reported uncertainties, so they are not statistically significant.

\section{Auxiliary Data}

The temperature profiles used initially were radiosonde measurements compiled from the stations around the launch site. These were subsequently refined and extended upward by using vmr profiles of $\mathrm{CO}_{2}$ derived from temperature-sensitive lines near 940 and $2390 \mathrm{~cm}^{-1}$. These spectral lines provide temperature profiles accurate to within a couple of kelvins as compared with colocated UARS measurements. In general, the temperature 
sensitivities of the fluorine absorptions used in this study are small, and so the error in the final temperature profile is not a significant source of error in slant columns.

The molecular spectral parameters used in the spectral fitting calculation were taken from the ATMOS compilation [Brown et al., 1996]. Spectroscopic parameters for the fluorine species described in the present work are reproduced in Table 1 . The systematic error in the retrieved burden, arising from using this spectroscopic compilation, is essentially due to uncertainties in absolute line strengths at $296 \mathrm{~K}$ and their temperature dependences. Changes in the former can be accounted for by a simple scaling of the gas burdens. However, a complete spectral fitting and vmr retrieval is necessary to incorporate corrections to the temperature dependence.

\section{Other Gases}

In addition to the fluorine species, spectral analyses were performed on many other gases including $\mathrm{CO}_{2}, \mathrm{~N}_{2} \mathrm{O}$, and $\mathrm{N}_{2}$. Solar zenith angles of the limb spectra were determined by constraining retrieved mixing ratios of $\mathrm{CO}_{2}$ to be consistent with in situ measurements [Schmidt and Khedim, 1991]. The retrieval of a long-lived tracer like $\mathrm{N}_{2} \mathrm{O}$ provides for studies of correlations among the many gases measured by MkIV and facilitates comparison with results of other instruments and models. An independent measure of the end-to-end analysis procedure was provided by $\mathrm{N}_{2}$ retrieval by using the lines near $2400 \mathrm{~cm}^{-1}$. The retrieved values ranged between 0.77 and 0.82 , having a rms deviation of only $1 \%$ over the 20 - to $35-\mathrm{km}$ altitude range from the known value of 0.78 . The systematic errors for these gases are largely due to pointing inaccuracies and uncertainties in the temperature profiles.

\section{Results and Discussions}

\section{Fluorine Source and Reservoir Gases}

In this section we describe briefly, for fluorine species listed in Table 1, the absorption features selected for spectral fitting and the retrieved $v m r$ profile. While MkIV observations of the

Table 1. Spectral Intervals and Line Parameters Used

\begin{tabular}{|c|c|c|c|}
\hline $\begin{array}{c}\text { Target } \\
\text { Gas }\end{array}$ & $\begin{array}{c}\text { Interval", } \\
\text { cm }^{-1}\end{array}$ & $\begin{array}{l}\Sigma \text { (strength), } \\
\text { cm. molec }^{-1}\end{array}$ & $\begin{array}{c}\text { Interfering } \\
\text { Gases }\end{array}$ \\
\hline $\begin{array}{l}\mathrm{CF}_{2} \mathrm{Cl}_{2} \\
\mathrm{CF}_{2} \mathrm{Cl}_{2}\end{array}$ & $\begin{array}{rr}921.80 & 3.60 \\
1160.90 & 1.50\end{array}$ & $\begin{array}{l}8.76 \times 10^{-18} \\
4.42 \times 10^{-18}\end{array}$ & $\begin{array}{l}\mathrm{CO}_{2}, \mathrm{H}_{2} \mathrm{O} \\
\mathrm{N}_{2} \mathrm{O}, \mathrm{O}_{3}\end{array}$ \\
\hline $\mathrm{CFCl}_{3}$ & 841.7035 .2 & $6.21 \times 10^{-17}$ & $\mathrm{HNO}_{3}, \mathrm{H}_{2} \mathrm{O}, \mathrm{CO}_{2}$ \\
\hline $\begin{array}{l}\mathrm{CHF}_{2} \mathrm{Cl} \\
\mathrm{CHF}_{2} \mathrm{Cl}\end{array}$ & $\begin{array}{ll}809.19 & 1.28 \\
829.14 & 0.72\end{array}$ & $\begin{array}{l}1.77 \times 10^{-18} \\
4.18 \times 10^{-19}\end{array}$ & $\begin{array}{l}\mathrm{O}_{3}, \mathrm{CO}_{2} \\
\mathrm{O}_{3}, \mathrm{CO}_{2}\end{array}$ \\
\hline $\mathrm{C}_{2} \mathrm{~F}_{3} \mathrm{Cl}_{3}$ & $815.57 \quad 23.9$ & $2.00 \times 10^{-17}$ & $\begin{array}{l}\mathrm{O}_{3}, \mathrm{CO}_{2}, \mathrm{H}_{2} \mathrm{O}, \mathrm{ClNO}_{3}, \\
\mathrm{CHF}_{2} \mathrm{Cl}\end{array}$ \\
\hline $\begin{array}{l}\mathrm{CF}_{4} \\
\mathrm{CF}_{4}\end{array}$ & $\begin{array}{ll}1283.00 & 2.00 \\
1285.26 & 2.22\end{array}$ & $\begin{array}{l}4.90 \times 10^{-17} \\
2.58 \times 10^{-17}\end{array}$ & $\begin{array}{l}\mathrm{CH}_{4}, \mathrm{~N}_{2} \mathrm{O} \\
\mathrm{CH}_{4}, \mathrm{~N}_{2} \mathrm{O}, \mathrm{H}_{2} \mathrm{O}\end{array}$ \\
\hline $\mathrm{SF}_{6}$ & $947.95 \quad 1.50$ & $3.31 \times 10^{-17}$ & $\mathrm{CO}_{2}, \mathrm{H}_{2} \mathrm{O}$ \\
\hline $\begin{array}{l}\mathrm{HF} \\
\mathrm{HF} \\
\mathrm{HF}\end{array}$ & $\begin{array}{ll}3877.72 & 0.30 \\
4038.90 & 0.65 \\
4109.95 & 0.30\end{array}$ & $\begin{array}{l}1.89 \times 10^{-18} \\
2.37 \times 10^{-18} \\
1.58 \times 10^{-18}\end{array}$ & $\begin{array}{l}\mathrm{H}_{2} \mathrm{O} \\
\mathrm{H}_{2} \mathrm{O}, \mathrm{CH}_{4} \\
\mathrm{CH}_{4}\end{array}$ \\
\hline $\begin{array}{l}\mathrm{COF}_{2} \\
\mathrm{COF}_{2} \\
\mathrm{COF}_{2} \\
\mathrm{COF}_{2}\end{array}$ & $\begin{array}{ll}1234.70 & 1.56 \\
1251.14 & 2.06 \\
1938.15 & 4.08 \\
1951.70 & 5.80\end{array}$ & $\begin{array}{l}1.78 \times 10^{-18} \\
2.43 \times 10^{-18} \\
3.45 \times 10^{-18} \\
4.98 \times 10^{-18}\end{array}$ & $\begin{array}{l}\mathrm{CO}_{2}, \mathrm{O}_{3}, \mathrm{CH}_{4} \\
\mathrm{~N}_{2} \mathrm{O}, \mathrm{CO}_{2}, \mathrm{CH}_{4} \\
\mathrm{H}_{2} \mathrm{O}, \mathrm{CO}_{2} \\
\mathrm{CO}_{2}, \mathrm{H}_{2} \mathrm{O}, \mathrm{O}_{3}\end{array}$ \\
\hline
\end{tabular}

* Central freouency and width of the spectral region analyzed.

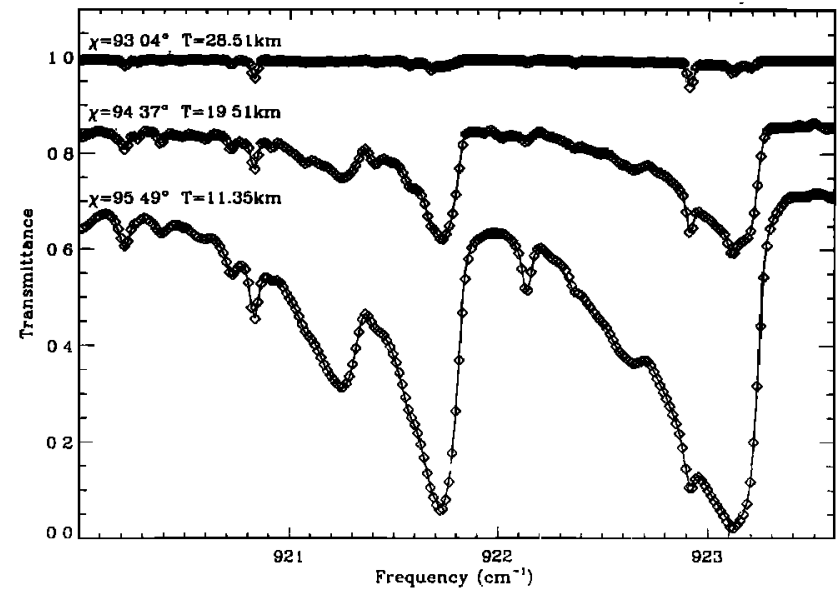

Figure 1. Three fitted limb spectra showing the growth of the $v_{6}$ $\mathrm{Q}$ branches of $\mathrm{CF}_{2} \mathrm{Cl}_{2}$ (CFC-12) versus tangent height. The spectra at lower tangent heights have been displaced for visual clarity. (In this and all subsequent spectral plots, the diamonds will show the measured spectral values, while the solid lines will show the fitted calculations.)

principal fluorine sources $\left(\mathrm{CF}_{2} \mathrm{Cl}_{2}, \mathrm{CFCl}_{3}\right.$, and $\left.\mathrm{CHF}_{2} \mathrm{Cl}\right)$ and reservoir (HF) have been presented before [Toon et al., 1989; Sen et al., 1995], they will be further discussed to assert our capability to measure fluorine loading in the atmosphere.

$\mathrm{CF}_{2} \mathrm{Cl}_{2}$ (CFC-12). CFC-12 was analyzed using its $\mathrm{Q}$ branches at 922 and $1161 \mathrm{~cm}^{-1}$. Although the latter region suffers from interference by $\mathrm{O}_{3}$ and $\mathrm{N}_{2} \mathrm{O}$, its stronger CFC-12 absorption allows retrievals to slightly higher altitudes. The spectroscopic parameters used in the analysis were derived from published high-resolution absorption cross-sections included in the ATMOS compilation [Brown et al., 1996]. These absorption cross sections were calculated from laboratory spectra acquired at atmospheric pressures and temperatures similar to those sampled by remote sensing instruments [Varanasi, 1992]. Using these cross sections, the two CFC-12 intervals exhibited a consistency of better than $1 \%$ in their slant columns.

Figure 1 shows three examples of observed (diamonds) and calculated (solid line) spectra used in the retrieval of CFC-12 in the $922 \mathrm{~cm}^{-1}$ region. The rapidly increasing slant column contribution of CFC-12 with decreasing tangent height emphasizes its tropospheric origin. The retrieved vmr profile of CFC-12 is included in Figure 2. The CFC-12 approaches a tropospheric value of 526 parts per trillion by volume (pptv) down at $5 \mathrm{~km}$, the minimum altitude to which vmr profiles were retrieved. We estimate a possible $8 \%$ systematic uncertainty due to the spectral parameters.

$\mathrm{CFCl}_{3}$ (CFC-11). CFC-11 ranks second to $\mathrm{CFC}-12$ in atmospheric abundance of anthropogenic fluorine source gases. Owing to the absence of sharp $Q$ branch-like features in the CFC-11 spectrum, the entire $v_{4}$ band between $830-860 \mathrm{~cm}^{-1}$ was fitted simultaneously.

The spectroscopic parameters for the analysis were again derived from the ATMOS compilations. An example of a spectral fit is shown in Figure 3. The interval is simultaneously fitted for CFC-1 1, $\mathrm{HNO}_{3}, \mathrm{CO}_{2}$, and $\mathrm{H}_{2} \mathrm{O}$. The retrieval gives a tropospheric value of about $290 \mathrm{pptv}$, in agreement with in situ measurements [Kaye et al, 1994]. Substantial uncertainties in retrieved CFC-11 are associated with the difficulties of fitting the continuum level on either side of the absorption band. This is particularly true in the $860 \mathrm{~cm}^{-1}$ region, in which $\mathrm{HNO}_{3}$ absorbs strongly. We 


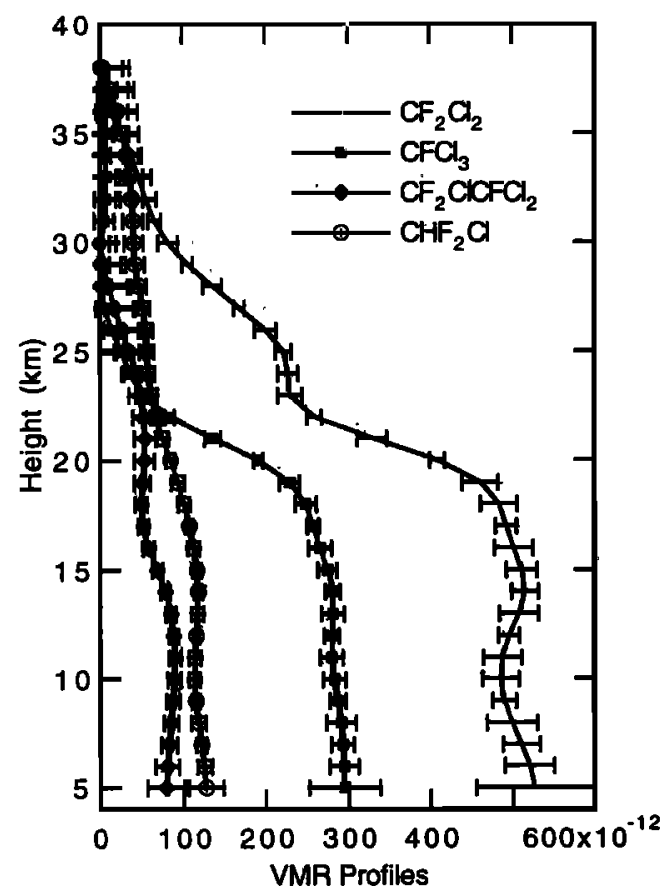

Figure 2. Retrieved vmr profiles of fluorine source gases $\mathrm{CF}_{2} \mathrm{Cl}_{2}$, $\mathrm{CFCl}_{3}, \mathrm{CF}_{2} \mathrm{ClCFCl}_{2}$, and $\mathrm{CHF}_{2} \mathrm{Cl}$.

estimate an $8 \%$ uncertainty due to the line list and a $5 \%$ uncertainty due to the difficulty in ascertaining the true continuum ( $9 \%$ total).

$\mathrm{CF}_{2} \mathrm{ClCFCl}_{2}$ (CFC-113). $\mathrm{CFC}-113$ is another important fluorine-bearing, anthropogenic, tropospheric source gas measured by the MkIV. It exhibits several featureless, broad absorptions in the mid-infrared, the most easily measured being the $v_{10}$ band in the $804-830 \mathrm{~cm}^{-1}$ region. Additionally, $\mathrm{CHF}_{2} \mathrm{Cl}$, $\mathrm{ClNO}_{3}, \mathrm{H}_{2} \mathrm{O}, \mathrm{CO}_{2}$, and $\mathrm{O}_{3}$ were also simultaneously fitted to accurately characterize the computed spectrum. Figure 4 illustrates a typical spectral fit. The strong equally spaced lines arising from $\mathrm{CO}_{2}$; the dashed line representing the absolute transmittance of CFC-113 alone calculated from the absorption cross sections of $M c$ Daniel et al. [1991]. Despite contributing no more than $8 \%$ absorptance in the illustrated spectrum, and overlapping the $\mathrm{R}$ branch of the $\mathrm{CHF}_{2} \mathrm{Cl} \mathrm{v}_{4}$ band, CFC- 113 can nevertheless be accurately quantified, since the $\mathrm{CHF}_{2} \mathrm{Cl}$ can be unambiguously determined from its $Q$ branches at 804.4 and $809.2 \mathrm{~cm}^{-1}$.

The retrieved vmr profile for CFC-113 is shown in Figure 2 and represents the first ever published using remote sensing techniques. The gas has a tropospheric value of 80-90 pptv, consistent with measurements reported by Kaye et al. [1994]. While its concentration, at the ground is small, CFC-113 nevertheless contributes $\approx 14 \%$ of the total tropospheric fluorine budget. We estimate a systematic error of $15 \%$ in the CFC-113 cross-sections [McDaniel et al., 1991] plus a $15 \%$ uncertainty in determining the continuum level and the $\mathrm{CHF}_{2} \mathrm{Cl}$ absorption (21\% total).

$\mathrm{CHF}_{2} \mathrm{Cl}$ (HCFC-22). Concern over environmental consequences of CFCs in the atmosphere have resulted in their replacement with shorter-lived gases, of which HCFC-22 is currently the most abundant. The retrieval of atmospheric HCFC-22 profile is based on the Q branches at 809.2 and 829.05 $\mathrm{cm}^{-1}$. Both intervals give results consistent to better than $1 \%$. The ability to detect and measure HCFC-22 is illustrated by Figure 5, in which the residual is almost at the level of spectrum noise. The vmr is very similar in profile to that measured by ATMOS in 1985 [Zander et al., 1992] but almost 89\% higher in tropospheric absolute value. It reflects the growth of this gas at the Earth's surface and its transport into the stratosphere, as also reported by Gunson et al. [1994]. The tropospheric value of about $125 \mathrm{pptv}$ is consistent with in situ measurements. The systematic uncertainty in retrieval due to the spectral line list is estimated to be $15 \%$.

$\mathbf{C F}_{4} . \mathbf{C F}_{4}$ is an inert gas widely used for low-temperature refrigeration and as an insulator in electrical subsystems, and it is also produced as a by-product of aluminum smelting. The chemical lifetime of $\mathrm{CF}_{4}$ is extremely long, and so it is expected to be well mixed throughout the troposphere and stratosphere.

$\mathrm{CF}_{4}$ is analyzed in the MkIV spectrum by fitting both its $\mathrm{Q}$ branch around $1283 \mathrm{~cm}^{-1}$ and the $\mathrm{R}$ branch at $1285 \mathrm{~cm}^{-1}$. In each case the target gas is fitted along with $\mathrm{N}_{2} \mathrm{O}, \mathrm{CH}_{4}$, and $\mathrm{H}_{2} \mathrm{O}$ to minimize errors they might introduce. Figure 6 shows a fit to the

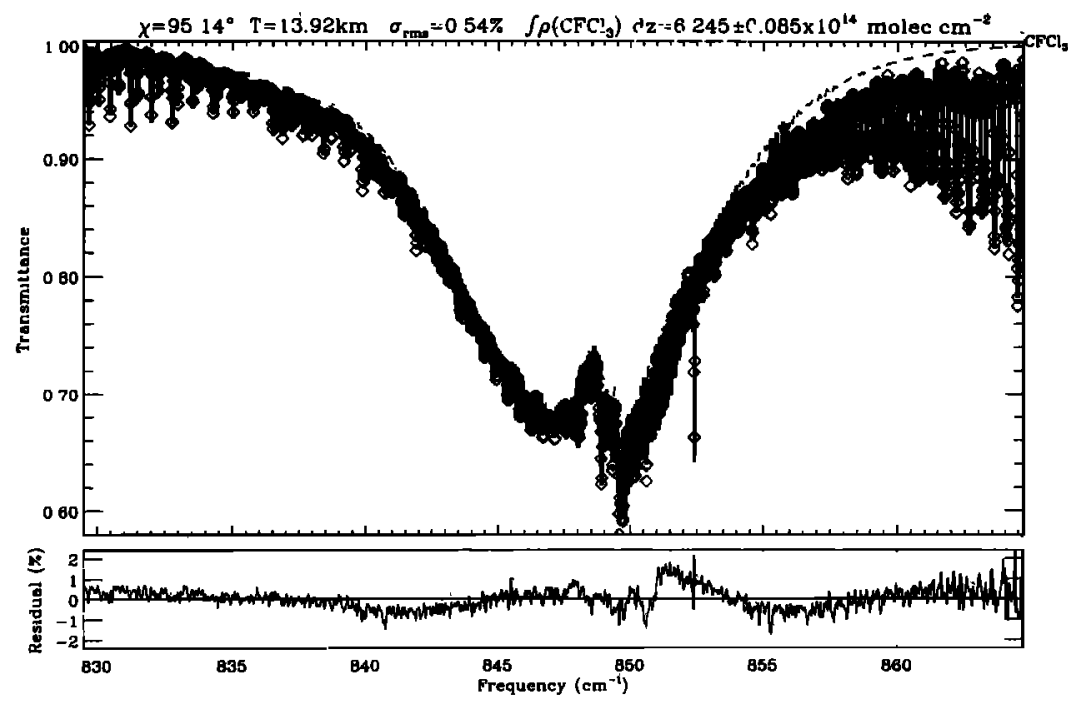

Figure 3. $\mathrm{CFCl}_{3}(\mathrm{CFC}-11)$ spectral fit at a tangent altitude of $13.9 \mathrm{~km}$. (In this and all subsequent spectral plots, the "residuals" are the enlarged differences between the measured and the calculated spectra. The dashed line shows the spectrum that would result from the target gas alone.) 


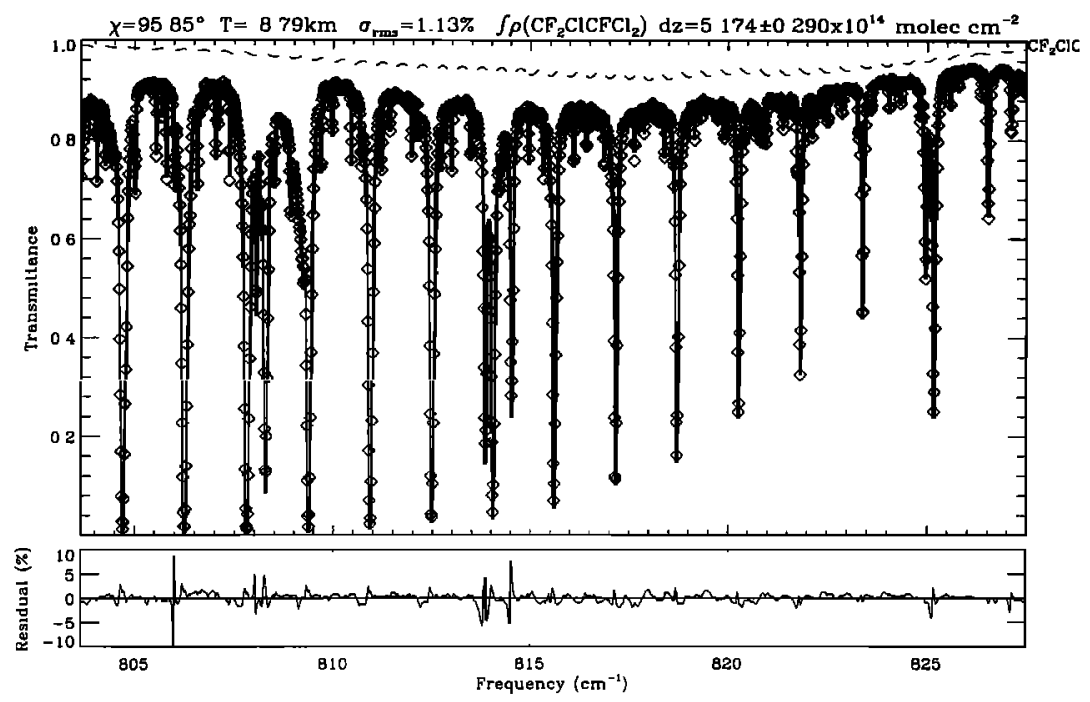

Figure 4. $\mathrm{CF}_{2} \mathrm{ClCFCl}_{2}$ (CFC-113) spectral fit at a tangent altitude of $8.8 \mathrm{~km}$.

broad $\mathrm{Q}$ branch of $\mathrm{CF}_{4}$ in a spectrum recorded for a tangent height of $26.37 \mathrm{~km}$. The strong lines arise from $\mathrm{CH}_{4}$ and $\mathrm{N}_{2} \mathrm{O}$ absorptions. The $\mathrm{CF}_{4}$ absorption is indicated by the dashed line. The derived vmr profile for $\mathrm{CF}_{4}$, along with all other fluorine sources and reservoirs, is tabulated in Table 2. The gas has an almost constant profile $(\approx 51 \mathrm{pptv})$ from $20 \mathrm{~km}$ up. However, throughout the troposphere the profile exhibits a monotonic decrease from $102 \mathrm{pptv}$ at $5 \mathrm{~km}$ to $59 \mathrm{pptv}$ at the tropopause. The best estimate of atmospheric lifetime of $\mathrm{CF}_{4}$ is more than 25,000 years [Ravishankara et al., 1993], far longer than the timescales of transport, thus suggesting that it should be well mixed vertically. The large monotonic decrease of $=50 \%$ in vmr from the middle to the upper troposphere is unexplained and awaits further review of the spectral interval. The $Q$ and $R$ branches of $\mathrm{CF}_{4}$ agree to within $4 \%$, and we estimate the current line parameters to contribute a $10 \%$ systematic error in the retrieval of the gas.

$\mathbf{S F}_{6} . \mathrm{SF}_{6}$ is a trace gas produced for use in high-voltage electrical and electronic equipment and has no known natural sources. The high chemical stability and long atmospheric residence time ( $>3200$ years) has also allowed $\mathrm{SF}_{6}$ to be used as a meteorological tracer. The gas is identified in the MkIV spectrum by its $Q$ branch at $947.9 \mathrm{~cm}^{-1}$ and can be retrieved over much of tangent altitude range in the September 1993 balloon flight.

The $\mathrm{Q}$ branch of $\mathrm{SF}_{6}$ is fitted in Figure 7 along with the more prominent $\mathrm{CO}_{2}$ and $\mathrm{H}_{2} \mathrm{O}$ lines. The broad $\mathrm{SF}_{6}$ absorption (947.7-948.0 $\mathrm{cm}^{-1}$ ) is overlapped by a weak but high ground state energy $\mathrm{CO}_{2}$ line $\left(E^{\prime \prime}=2614 \mathrm{~cm}^{-1}\right)$. However, the entire absorption is much wider than the $\mathrm{CO}_{2}$ and thus can be clearly distinguished from it. Our upper tropospheric vmr of $3.2 \mathrm{pptv}$ (Table 2) is consistent with the 1985 ATMOS measurements when the published global average exponential increase rate of $10.5 \% / \mathrm{yr}$ is considered [Rinsland et al., 1990]. While the spectroscopic uncertainty for $\mathrm{SF}_{6}$ is estimated to be $10 \%$, larger systematic uncertainties may arise in the troposphere as the interfereing $\mathrm{CO}_{2}$ lines pressure broaden. This is reflected in the large lower tropospheric $\mathrm{SF}_{6}$ errors reported in Table 2.

HF. HF was retrieved by using the P2, R1, R3 lines of its 1-0 transitions, as described by Sen et al. [1995]. The stratospheric origin of HF is apparent in Figure 8 in plotting fitted spectra at three tangent heights. The number density in the retrieved profile

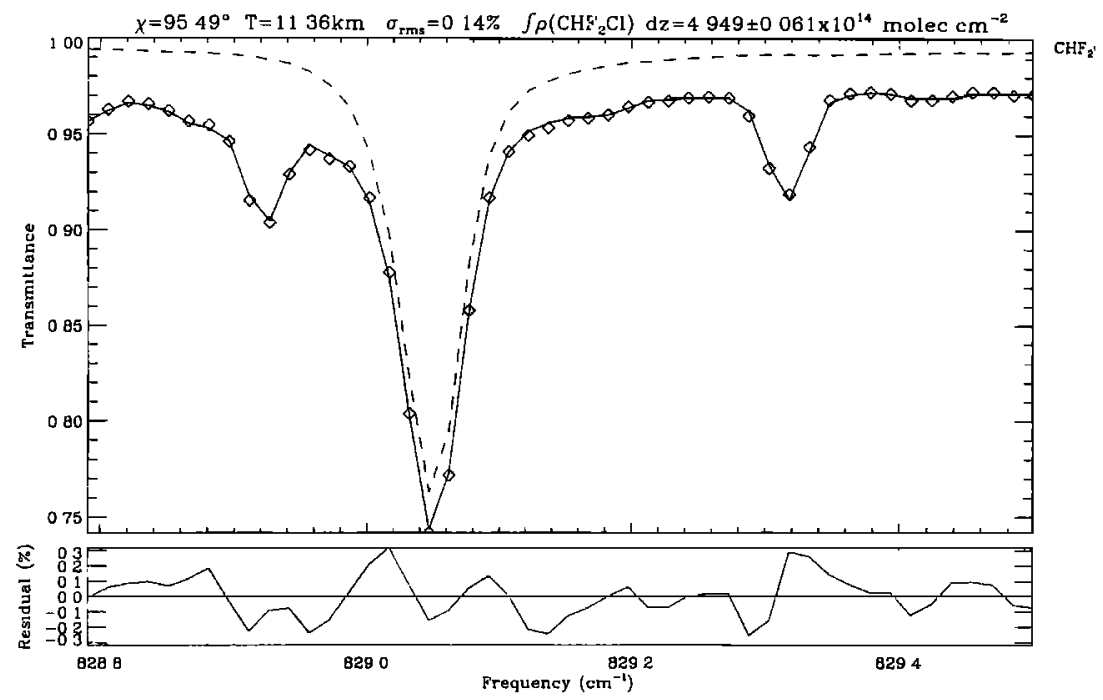

Figure 5. $\mathrm{CHF}_{2} \mathrm{Cl}(\mathrm{HCFC}-22)$ spectral fit at a tangent altitude of $11.3 \mathrm{~km}$. 


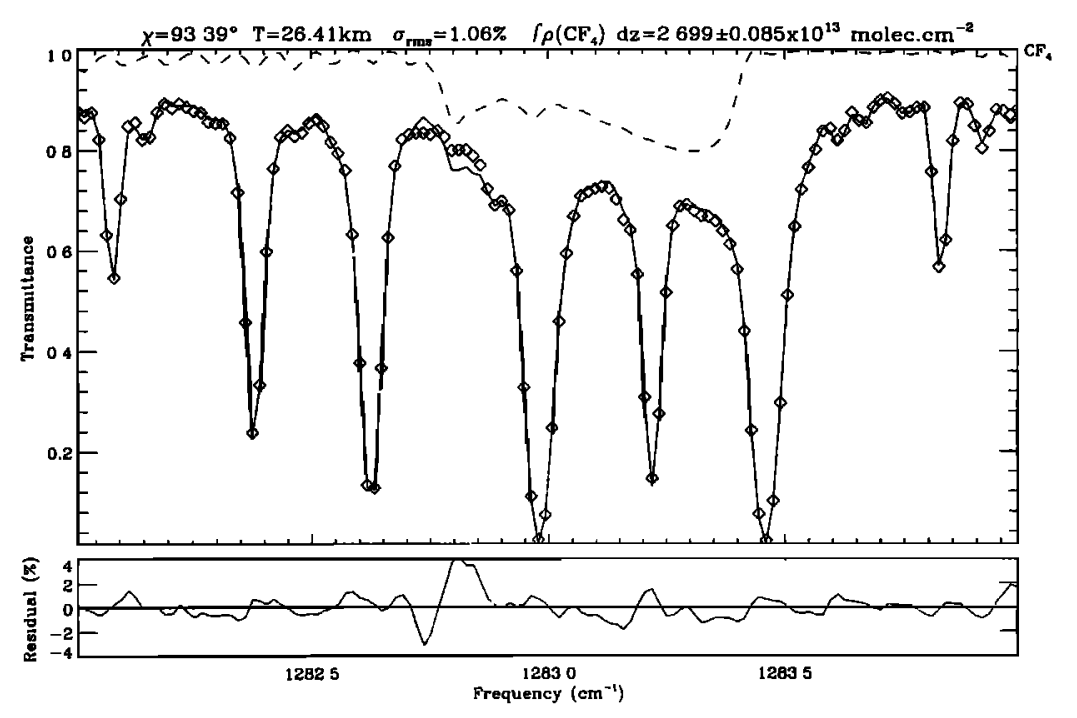

Figure 6. $\mathrm{CF}_{4}$ spectral fit at a tangent altitude of $26.4 \mathrm{~km}$.

peaks at around $22 \mathrm{~km}$ and is well reflected in the stronger absorption signature in the middle spectrum. $\mathrm{CH}_{4}$ and $\mathrm{H}_{2} \mathrm{O}$ are the primary interfering gases and have been simultaneously fitted to minimize their impact on the HF.

The vmr profiles of both $\mathrm{HF}$ and $\mathrm{COF}_{2}$ are reproduced in Figure 9. HF approaches a stratospheric value of 1.10 parts per billion by volume (ppbv) at $38 \mathrm{~km}$, a value commensurate with 1992 ATMOS observations [Zander et al., 1994]. The retrieved profile includes an inflection at around $23-25 \mathrm{~km}$ altitude. As similar features are also present in all the long-lived trace gases retrieved (e.g., $\mathrm{N}_{2} \mathrm{O}$ and $\mathrm{CFC}-12$ ), they can be attributed to transport effects and not chemical changes in HF. The three 1-0 transition lines of HF agree to better than $1 \%$, and the systematic uncertainty from the line list is less than $3 \%$.

$\mathrm{COF}_{2}$. The JPL MkIV spectra cover all the $\mathrm{COF}_{2}$ absorption features observed in the laboratory, including those around 1938 $\mathrm{cm}^{-1}$ used by ATMOS for retrieval of the gas [Zander et al., 1994]. Retrievals performed by using manifolds at $1951 \mathrm{~cm}^{-1}$ (Figure 10) were found to have better precision than the ones centered around 1234,1251 , or $1938 \mathrm{~cm}^{-1}$. Weighted slant column abundances from all four spectral intervals were used in this study, although they differ from one another by only $1.5 \%$. The spectroscopic uncertainty in the retrieved $\mathrm{COF}_{2}$ profile is about $10 \%$. The $\mathrm{COF}_{2}$ profile in the midlatitude stratosphere peaks at $31 \mathrm{~km}$ to a maximum value of $230 \mathrm{pptv}$, agreeing well with 1992 ATMOS observations [Zander et al., 1994].

COFCl. The only significant fluorine reservoir not measured by the $\mathrm{MkIV}$ is $\mathrm{COFCl}$. The principal region of $\mathrm{COFCl}$ absorption (1850-1908 $\mathrm{cm}^{-1}$ ) is dominated by spectroscopic signatures of the immensely more abundant gases $\mathrm{O}_{3}$ and $\mathrm{CO}_{2}$, making the fluorine species impossible to even detect. The gas arises primarily from the photolysis of $\mathrm{CFCl}_{3}$ in the lower stratosphere. Since $\mathrm{COFCl}$ is believed to be the most easily photolyzed fluorine reservoir, its vmr should fall off rapidly with increasing altitude above its peak [Kaye et al., 1991]. The vmr profile of $\mathrm{COFCl}$ used in this study, Figure 9 (dashed line), is a Goddard Space Flight Center (GSFC) 2-D model calculation representing the conditions in September 1993 at a latitude of $35^{\circ} \mathrm{N}$ (time and latitude of MkIV sunset). The profile peaks to a value of $83 \mathrm{pptv}$ at an altitude of $26 \mathrm{~km}$ and practically disappears above $35 \mathrm{~km}$. Its contribution to the midlatitude fluorine budget is at most $6 \%$ in the altitude range below $30 \mathrm{~km}$. We estimate a $12 \%$ systematic uncertainty in the $\mathrm{COFCl}$ profile from the measurements and model results summarized by Zander et al. [1992].

\section{Midlatitude Fluorine Abundance}

Having no major photochemical sinks, $\mathrm{CF}_{4}$ and $\mathrm{SF}_{6}$, maintain their characteristic throughout the troposphere and stratosphere and therefore play no role in the conversion of fluorine sources into reservoirs. For this reason the constant biases of $\mathrm{CF}_{4}$ and $\mathrm{SF}_{6}$ to the total fluorine budget are usually ignored [WMO, 1991; Zander et al., 1994]. We continue this convention in this paper, although measured values are still provided in Table 2.

The sum of measured (symbols) and modeled (solid lines) fluorine sources $\left(\mathrm{CF}_{2} \mathrm{Cl}_{2}, \mathrm{CFCl}_{3}, \mathrm{CF}_{2} \mathrm{ClCFCl}_{2}\right.$, and $\left.\mathrm{CHF}_{2} \mathrm{Cl}\right)$ and reservoirs ( $\mathrm{HF}, \mathrm{COF}_{2}$, and $\mathrm{COFCl}$ ) is illustrated in Figure 11 along with model predictions. The use of $\mathrm{N}_{2} \mathrm{O}$ as a vertical ordinate, in place of altitude or pressure, allows a more exacting model comparison by removing any transport-induced transients in the individual profiles. The fluorine-weighted sum of all fluorine reservoirs and their sources is listed in the last column of Table 2 . The uncertainty in the total was not simply calculated by the root-sum-square (rss) of the individual fluorine-weighted errors, because this quantity becomes dominated by the most poorly measured gas, even when its contribution to the sum of total fluorine is negligible. Instead, the uncertainty in this total is the fluorine-weighted rss of the constrained error in each gas. The constrained error is the weighted mean of (1) the retrieval precision plus the fractional systematic error in the retrieval and (2) the uncertainty in the a priori profile for each gas (assumed to be half the peak vmr value). The constrained error thus assumes a value close to the latter at heights at which the MkIV is unable to accurately measure a fluorine species.

The total fluorine above $35 \mathrm{~km}$ (virtually all $\mathrm{HF}$ and $\mathrm{COF}_{2}$ ) was $1.48 \mathrm{ppbv}$, in agreement with recent ATMOS observations [Zander et al., 1994]. The value is consistent with the mean tropospheric abundance of fluorine (excluding contributions from $\mathrm{CF}_{4}$ and $\mathrm{SF}_{6}$ ) for 1988-1989 (WMO, 1991). This finding indicates a 4- to 5-year temporal delay for the fluorine in long-lived source gases, released at the ground, to be observed above $35 \mathrm{~km}$. This transport time is in good agreement with the $\mathrm{CO}_{2} \mathrm{vmr}$ 


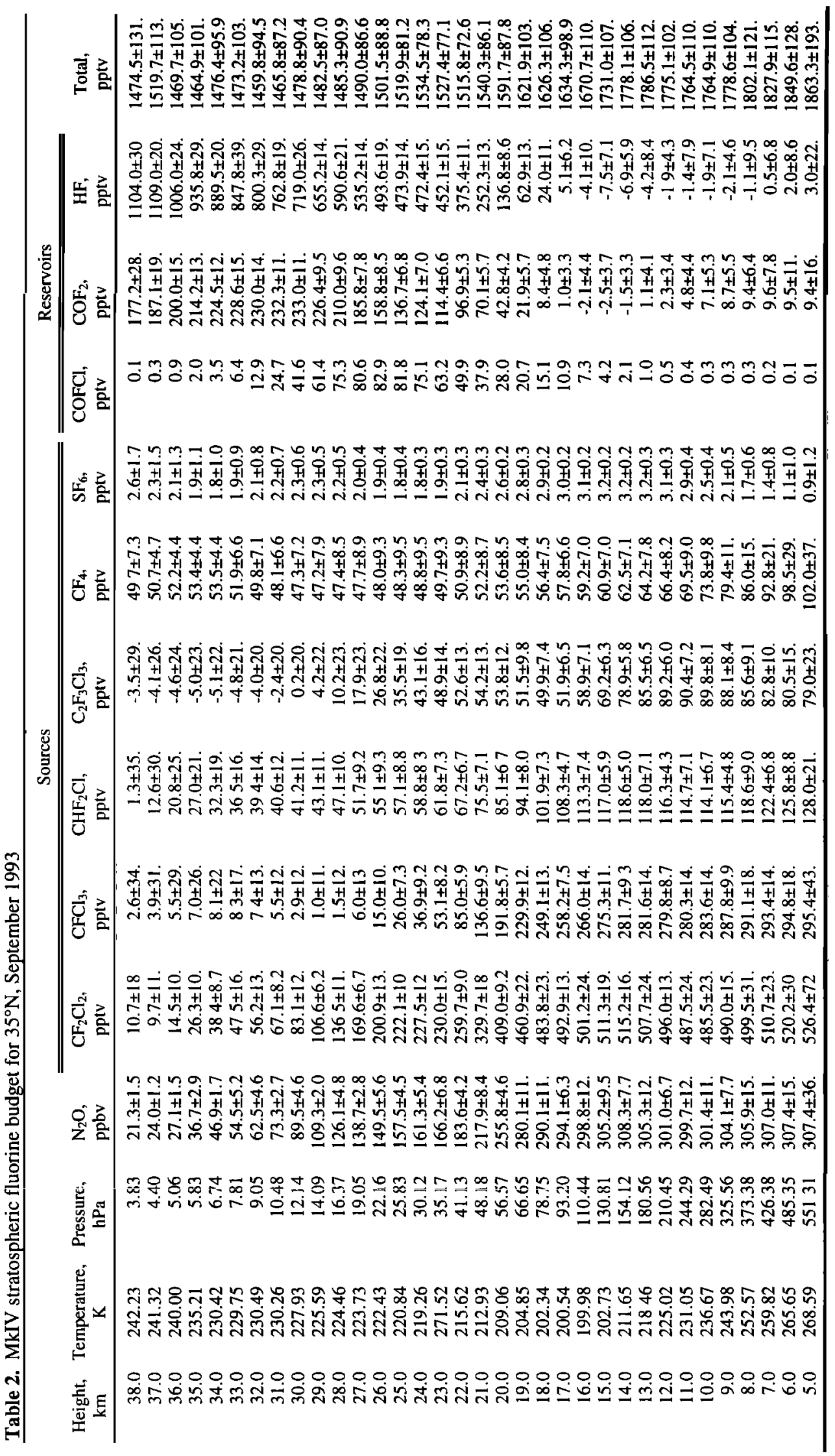




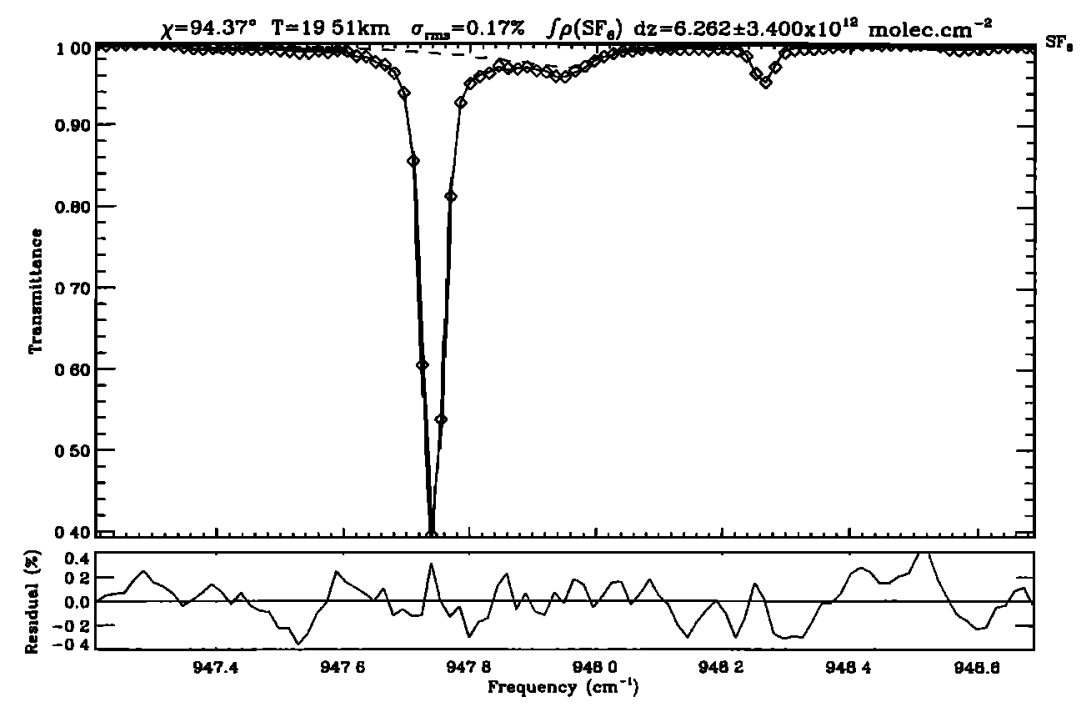

Figure 7. $\mathrm{SF}_{6}$ spectral fit at a tangent altitude of $19.5 \mathrm{~km}$. The strong $\mathrm{CO}_{2}$ line at $947.74 \mathrm{~cm}^{-1}$ dominates this interval. A weaker high-ground state energy $\left(E^{\prime \prime}=2416.4 \mathrm{~cm}^{-1}\right) \mathrm{CO}_{2}$ line at $947.94 \mathrm{~cm}^{-1}$ overlaps the peak $\mathrm{SF}_{6}$ absorption.

measurements of Schmidt and Khedim [1991]. Hall and Prather [1993], modeling an ensemble of $\mathrm{CO}_{2}$ air masses of different ages, computed a mean delay of 4 years between the parcel's characterization in the troposphere and at $30 \mathrm{~km}$. The model value is in good agreement with MkIV observations when considering the altitude differences and the caveat that the computed mean age is valid only for $\mathrm{CO}_{2}$ concentration varying linearly with time.

Our total tropospheric fluorine was observed to be $1.82 \pm 0.05$ ppbv. This sum does not include the contributions from the fluorine-containing organobromine species $\left(\mathrm{CBrF}_{3}\right.$ and $\left.\mathrm{CBrClF}_{2}\right)$, owing to the lack of knowledge of their tropospheric vmr profiles. However, by using the National Oceanic and Atmospheric Administration Climate Monitoring and Diagnostic Laboratory measurements of 2 and $2.5 \mathrm{pptv}$, respectively [WMO, 1994], the organobromine species contribute no more than 11 pptv $(0.6 \%)$ to our fluorine budget at the ground and have therefore been ignored. On the basis of tropospheric measurements summarized by WMO [1991] the total concentration of fluorine-containing gases $\left(\mathrm{CF}_{2} \mathrm{Cl}_{2}, \mathrm{CFCl}_{3}, \mathrm{CF}_{2} \mathrm{ClCFCl}_{2}, \mathrm{CHF}_{2} \mathrm{Cl}, \mathrm{CBrClF}_{2}\right.$, and $\mathrm{CBrF}_{3}$ ) was $1.58 \mathrm{ppbv}$ in 1990 and increasing $5.2 \%$ per year. The 1993 measurements by MkIV are therefore in good agreement with tropospheric measurements in 1990 when the rate of increase is considered.

We also compare the MkIV measurements with calculations from GSFC 2-D model. The model fluorine chemistry is described in Kaye et al. [1991], and a general model description is contained in the works by Fleming et al. [1995] and Sen et al. [1995]. The fluorine budget from the model calculation is overlaid on the MkIV results in Figure 12. The time-dependent model runs were performed for latitude and time encompassing the September 1993 MkIV balloon flight. The model run for

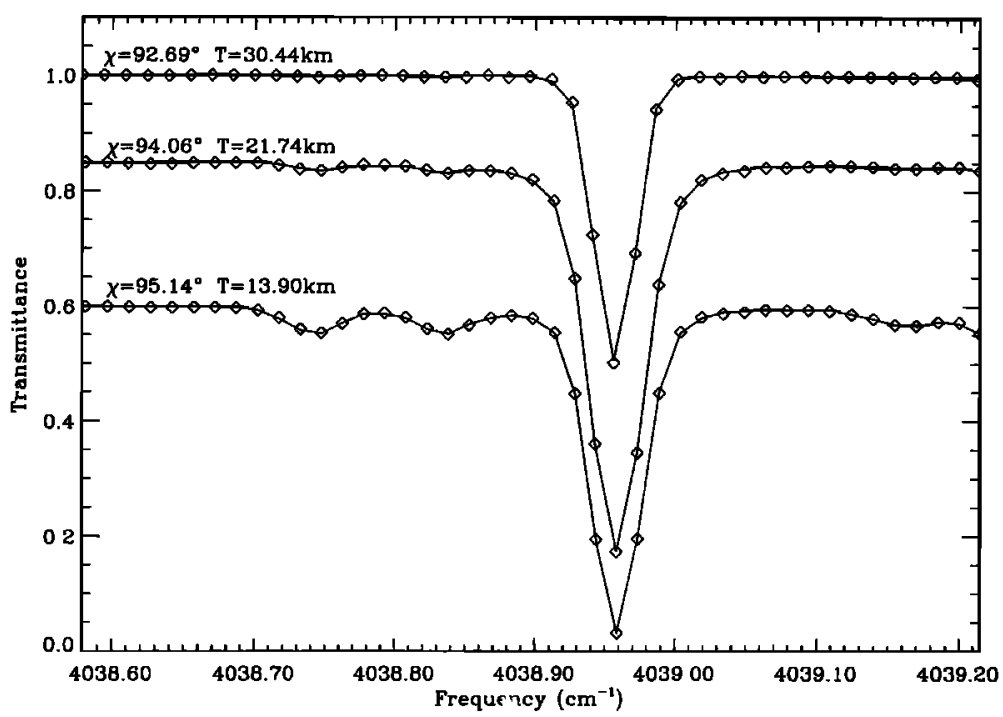

Figure 8. Three spectral fits of the R1 line of the fundamental band of HF. Spectra at lower tangent heights have been displaced for visual clarity. 


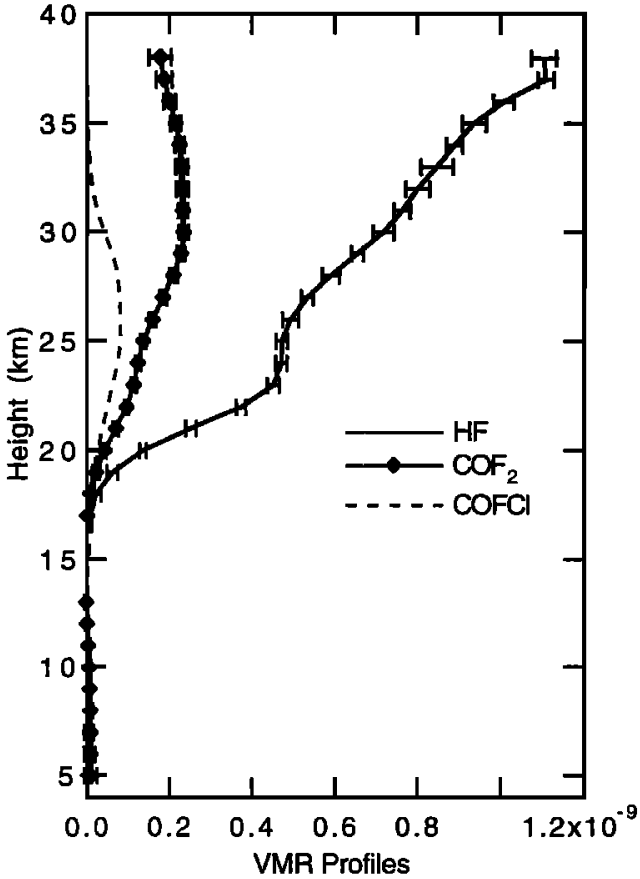

Figure 9. Retrieved vmr profiles of fluorine reservoir gases. COFCl profile (dashed line) is a time-dependent GSFC 2-D model calculation performed for the time and latitude of MkIV observations.

September 1993 was initialized with source CFCs and HCFCs emissions characteristic detailed by WMO (1991), and the total fluorine of $1.79 \mathrm{ppbv}$ is consistent with MkIV observations. The model predicts a total fluorine of about $1.45 \mathrm{ppbv}$ at $38 \mathrm{~km}$, in reasonable agreement with MkIV observations. Further, by comparing the time evolution of fluorine reservoirs at $60 \mathrm{~km}$ to the source concentrations used as yearly input into the model, an "age" of $\approx 6$ years is derived for transport to $60 \mathrm{~km}$ altitude. This is consistent with results from the current study. Figure 12 also demonstrates the tight quantitative relation between fluorinated source gases released at the ground and the fluorine budget measured above $35 \mathrm{~km}$. It clearly contradicts the earlier

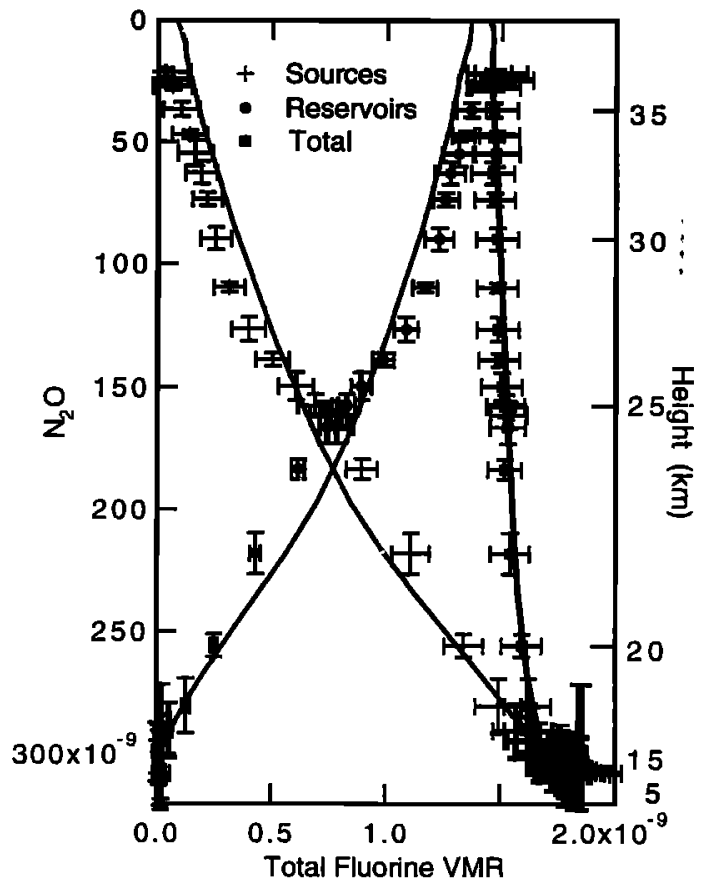

Figure 11. Total fluorine budget measured by MkIV at $35^{\circ} \mathrm{N}$ in September 1993. The profiles correspond to budgets of fluorine (Table 2) incorporating six of the measured gases (CFC-12, CFC-1 1, CFC-113, HCFC-22, HF, and $\mathrm{COF}_{2}$ ) and a gas (COFCl) from the GSFC 2-D model. Symbols show the fluorine budget measured by the MkIV, and the solid lines represent the model calculations.

hypothesis that intense volcanic eruptions inject large amounts of HF into the stratosphere (Symonds et al., 1978). The gradients of both the measurements and the model predictions illustrated in Figure 12 are greater than -1 , mostly because HF diffuses down into the troposphere (Sen et al., 1995) and is lost owing to rainout, diminishing the amount of fluorine throughout the stratosphere. The time lag of fluorine in going from source to reservoir is also a contributor but is less of an effect than the rainout.

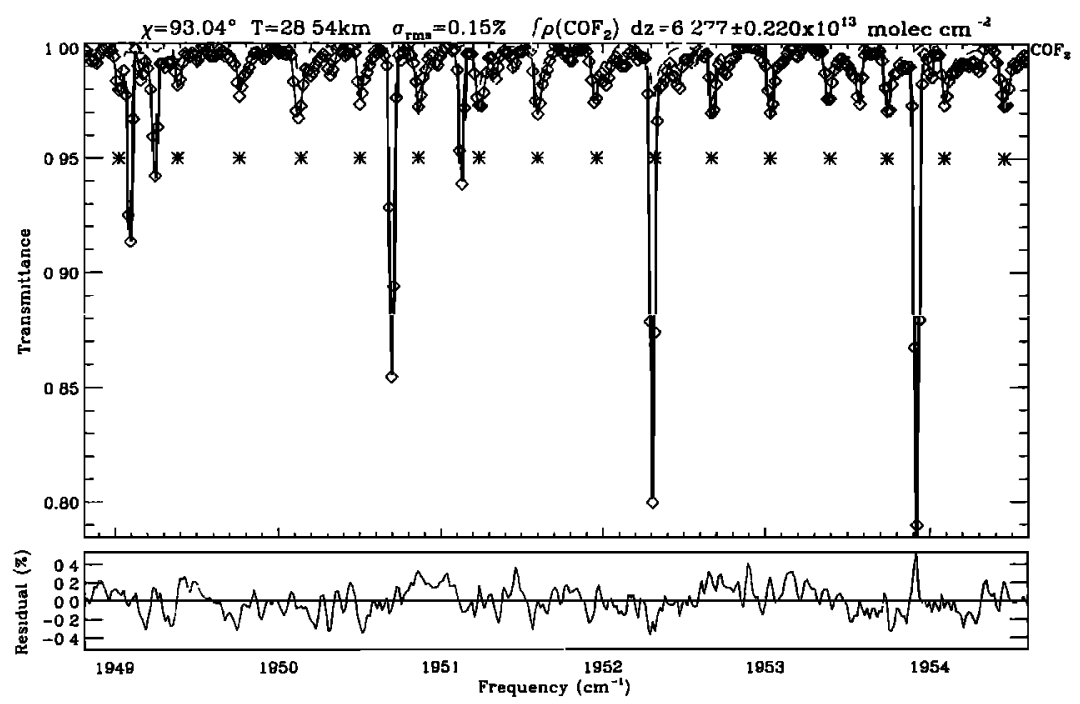

Figure 10. $\mathrm{COF}_{2}$ spectral fit at a tangent altitude of $28.5 \mathrm{~km}$. The 16 strongest manifolds of $\mathrm{COF}_{2}$ are indicated by asterisks. 


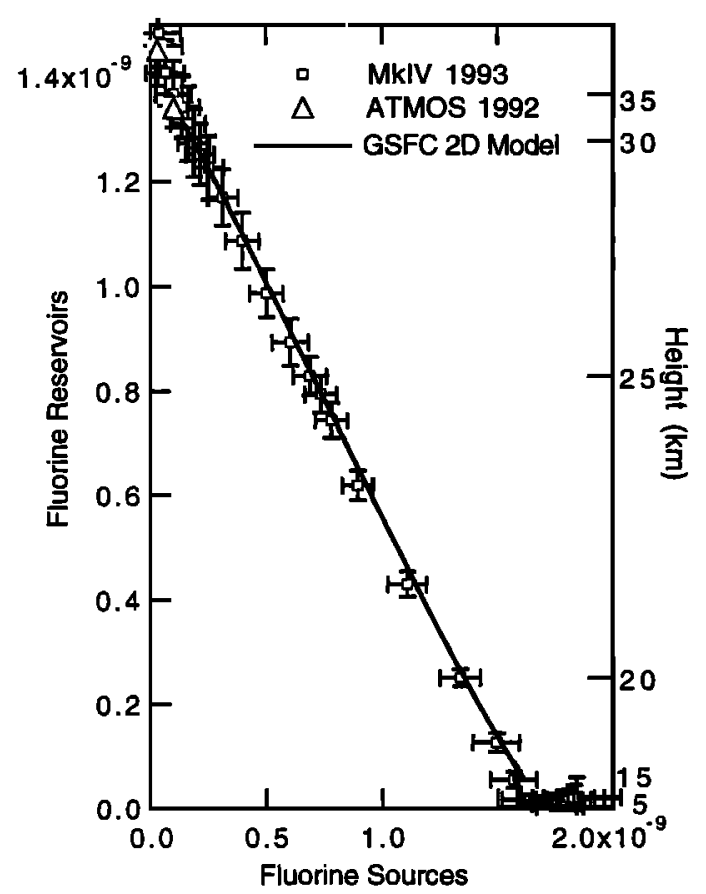

Figure 12. Total fluorine in the reservoir species versus the sources. The figure demonstrates the tight inverse correlation between fluorine sources and their reservoirs.

\section{Summary}

This study has dealt with determining the fluorine budget in the stratosphere by using high-resolution infrared solar observations of $\mathrm{CF}_{2} \mathrm{Cl}_{2}, \mathrm{CFCl}_{3}, \mathrm{CF}_{2} \mathrm{ClCFCl}_{2}, \mathrm{CHF}_{2} \mathrm{Cl}, \mathrm{CF}_{4}, \mathrm{SF}_{6}$, $\mathrm{HF}$, and $\mathrm{COF}_{2}$ from a high-altitude research balloon. These species comprise $94-99 \%$ of total fluorine, depending on altitude. This is the first time all of these species have been measured simultaneously in the same spectrum, eliminating uncertainties which arise if the different gases are measured in different locations [e.g., Zander et al. 1992]. The total fluorine in September 1993 was $1.48 \pm 0.05$ ppbv over the 35 - to $38-\mathrm{km}$ range and $1.82 \pm 0.05 \mathrm{ppbv}$ in the troposphere. Within the uncertainties of the MkIV measurements the stratospheric fluorine budget is consistent with tropospheric values in 1988-1989, confirming that the origin of stratospheric fluorine reservoir gases is tropospheric sources. The observed fluorine budget is in agreement with ATMOS measurements and GSFC 2-D model predictions demonstrating that the latter reasonably represents both the chemistry and transport of fluorine source and reservoir species.

Acknowledgments. The authors wish to thank D.C.Petterson, J.H.Riccio, R.D.Howe, and W.B.Wilson of the Jet Propulsion Laboratory for their considerable assistance in operation of JPL MkIV during the balloon flight, and the National Scientific Balloon Facility who conducted the balloon launches, flight operations and recovery of the payload. This research was performed at the Jet Propulsion Laboratory, California Institute of Technology, under contract with the National Aeronautics and Space Administration.

\section{References}

Brown, L.R., M.R. Gunson, R.A. Toth, F.W. Irion, C.P. Rinsland, and A. Goldman, The 1995 atmospheric trace molecule spectroscopy (ATMOS) linelist, Appl. Opt., in press, 1996.
Fleming, E.L., S. Chandra, C.H. Jackman, D.B. Considine, and A.R. Douglass, The middle atmospheric response to short and long term solar UV variations: analysis of observations and 2D model results, $J$. Atmos. Terr. Phys., 57, 333-365, 1995.

Gunson, M.R., M.C. Abrams, L.L. Lowes, E. Mahieu, R. Zander, C.P. Rinsland, M.K.W. Ko, and D.K. Weinsenstein, Increase in levels of stratospheric chlorine and fluorine loading between 1985 and 1992, Geophys. Res. Lett., 21, 2223-2226, 1994.

Hall, T.M., and M.J. Prather, Simulations of the trend and annual cycle of stratospheric $\mathrm{CO}_{2}$, J. Geophys. Res., 98, 10573-10581, 1993.

Kaye, J.A., A.R. Douglass, C.H. Jackman, R.S. Stolarski, R. Zander, and G. Roland, Two-dimensional model calculation of fluorine-containing reservoir species, J. Geophys. Res., 96, 12865-12881, 1991.

Kaye, J.A., S.A. Penkett, and F.M. Ormond, (Eds.), Reports on concentrations, lifetimes, and trends of cfc's, halons, and related species, NASA Ref. Pub. 1339, 1994.

McDaniel, A.H., C.A. Cantrell, J.A. Davidson, R.E. Shetter, and J.G. Calvert, The temperature dependent, infrared absorption cross sections for the chlorofluorocarbons: CFC-11, CFC-12, CFC-13, CFC-14, CFC-22, CFC-113, CFC-114, and CFC-115, J. Atmos. Chem., 12, 211-227, 1991 .

Ravishankara, A.R., S. Solomon, A.A. Turnipseed, and R.F. Warren, Atmospheric lifetimes of long-lived halogenated species, Science, 259, 194-199, 1993.

Rinsland, C.P., L.R. Brown, and C.B. Farmer, Infrared spectroscopic detection of sulfur hexafluoride $\left(\mathrm{SF}_{6}\right)$ in the lower stratosphere and upper troposphere, J. Geophys. Res., 95, 5577-5585, 1990.

Schmidt, U., and A. Khedim, In situ measurements of carbon dioxide in the winter Arctic vortex and at midlatitudes: An indicator of the "age" of stratospheric air, Geophys. Res. Lett., 18, 763-766, 1991.

Sen, B., G.C. Toon, J.-F. Blavier, J.T. Szeto, E.L. Fleming, C.H. Jackman, Balloon-borne observations of midlatitude hydrofluoric acid, Geophys. Res. Lett., 22, 385-388, 1995.

Stolarski, R.S., and R.D. Rundel, Fluorine photochemistry in the stratosphere, Geophys. Res. Lett., 2, 433-434, 1975.

Symond, R.B., W.I. Rose, and M.H. Reed, Contribution of Cl- and Fbearing gases to the atmosphere by volcanoes, Nature, 334, 415-418, 1978.

Toon, G.C., C.B. Farmer, L.L. Lowes, -P.W. Schaper, J.-F. Blavier, and R.H. Norton, Infrared aircraft measurements of stratospheric composition over Antarctica during September 1987, J. Geophys. Res., 94, 16571-16596, 1989.

Toon, G.C., The JPL MkIV interferometer, Opt. Photonics News, 2, 19-21, 1991.

Varanasi, P., Absorption-coefficients of CFC-11 and CFC-12 needed for atmospheric remote-sensing and global warming studies, J. Quant. Spectrosc. Radiat. Transfer., 48, 205-219, 1992.

World Meteorological Organization, Scientific assessment of ozone depletion: 1991, Rep. 25, Geneva, Switzerland, 1991.

World Meteorological Organization, Scientific assessment of ozone depletion: 1994, Rep. 37, Geneva, Switzerland, 1994.

Zander, R., M.R. Gunson, C.B. Farmer, C.P. Rinsland, F.W. Irion, and E. Mahieu, The 1985 chlorine and fluorine inventories in the stratosphere based on ATMOS observations at $30^{\circ}$ north latitude, J. Atmos. Chem. IS, 171-186, 1992.

Zander, R., C.P. Rinsland, E. Mahieu, M.R. Gunson, C.B. Farmer, M.C. Abrams, and M.K.W. Ko, Increase of carbonylfluoride $\left(\mathrm{COF}_{2}\right)$ in the stratosphere and its contribution to the 1992 budget of inorganic fluorine in the upper stratosphere, J. Geophys. Res., 99, 16737-16743, 1994.

E.L. Fleming, Applied Research Corporation, Landover, MD 20785. C.H. Jackman, Laboratory for Atmospheres, NASA Goddard Space Flight Center, Greenbelt, MD 20771.

B. Sen, G.C. Toon, and J.-F. Blavier, Jet Propulsion Laboratory, Califomia Institute of Technology, M.S. 183-301, 4800 Oak Grove Drive, Pasadena, CA, 91109. (e-mail: sen@mark4sun.jpl.nasa.gov)

(Received July 20, 1994; revised November 16, 1995; accepted November 16, 1995.) 